\title{
Cytarabine Subcutaneous Regimen
}

National Cancer Institute

\section{Source}

National Cancer Institute. Cytarabine Subcutaneous Regimen. NCI Thesaurus. Code C160016.

A chemotherapy regimen consisting of subcutaneous cytarabine that may be used in the treatment of acute myeloid leukemia (AML). 